\title{
CONSTRUÇÕES SUSTENTÁVEIS: O ASPECTO SOCIAL E O DESAFIO CULTURAL NA
}

\section{ENGENHARIA CIVIL}

Claudia Anahi Aguilera Larrosa ${ }^{1}$

Liane da Silva Bueno²

\section{RESUMO}

Este artigo apresenta uma reflexão a respeito das construções sustentáveis. Define, e de forma sucinta identifica a atual abrangência deste tema na realidade brasileira. Uma contextualização para apoiar estudos acadêmicos de um assunto inovador e, que pela sua relevância na formação de um profissional de Engenharia Civil, propõem uma leitura esclarecedora a respeito do tema, afim de conduzir novas posturas nas futuras decisões técnicas, pautadas pelo desenvolvimento sustentável da construção civil. Portanto, reflete a quebra de paradigmas, quanto as tecnologias dos materiais e métodos construtivos, o aspecto social e o desafio cultural das intervenções sustentáveis nos espaços urbanos.

Palavras-Chave: Construção sustentável. Aspecto Social. Aspecto Cultural. Espaços urbanos. Engenharia Civil.

\section{ABSTRACT}

This article presents a reflection about the sustainable constructions. Defines and succinctly identifies the current scope of this theme in the brazilian reality. A context to support academic studies of something innovative and that by your importance in the formation of a professional Civil Engineering, propose a reading enlightening on the subject, in order to drive new postures in future technical decisions, grounded by the sustainable development of civil construction. Therefore, it reflects the

1 Professora do IFSUL no Campus Avançado Jaguarão/RS. Doutoranda do Programa de PósGraduação em Engenharia Civil (PPGCI) da Universidade Federal do Rio Grande do Sul (UFRGS). email: claudialarrosa@ifsul.edu.br.

2 Coordenadora e Professora do Curso de Engenharia Civil da Universidade Alto Vale do Rio do Peixe (UNIARP). Mestre em Engenharia Civil e Doutora em Engenharia de Produção com ênfase em Gestão Ambiental pela Universidade Federal de Santa Catarina (UFSC).Email: lianebueno@gmail.com. 
breaking of paradigms, as the technologies of materials and construction methods, the social aspect and the cultural challenge of sustainable interventions in urban spaces.

Keywords: Sustainable construction. Social. Cultural. Urban spaces. Civil Engineering.

\section{INTRODUÇÃO}

Estudos relacionados do papel social das propriedades a muito tem sido estudado, pesquisado, buscando a sustentabilidade territorial dos usos dos solos, como é o caso dos estudos das áreas de ocupação com fatores de risco (Bueno, 2000), bem como o avanço das leis ambientais, dentre outros tem-se (Maricato, 2017), que reflete a respeito da melancolia a respeito das desigualdades urbanas.

Salientando-se que a realidade das cidades brasileiras até então vem desenvolvendo-se numa perspectiva territorial que retrata a impregnação dos quatrocentos anos de escravidão no país, onde os centros urbanos assemelham-se a casa grande, e as regiões periféricas as senzalas, conforme reflete (Maricato, 2017).

Frente esta realidade, busca-se pensar a cidade de forma democrática. Para tanto, induz-se reflexões sobre as moradias sustentáveis; as construções sustentáveis, atendendo ao cumprimento do caráter social, afirmando-se ser estas, um dos principais atores na composição deste cenário, ou seja, pensar as cidades de forma responsável, além do saber construir de forma integrada em harmonia com entorno, garantir as futuras gerações mobilidade urbana e o meio ambiente sustentável.

\section{CONSTRUÇÃO}

Segundo CARDÃO (1988), as técnicas da construção estão relacionadas ao que se refere ao conhecimento dos materiais, a resistência dos materiais, aos métodos construtivos e ao conhecimento da arte. Destaca o edifício como toda construção que se destina ao abrigo e proteção contra as intempéries e contra as ações provocadas pelo homem frente sua relação social, seus bens materiais e espirituais. 


\section{CONSTRUÇÃO SUSTENTÁVEL}

Para SATTLER (2017), existe uma definição para sustentabilidade, onde para sermos sustentáveis deveremos aprender a "viver dentro da capacidade de suporte do planeta". Esta definição, se aplicada a construções, sugere que construamos dentro desta "capacidade de suporte".

Por outro lado, o Relatório Planeta Vivo 2016, do WWF, sugere que, com uma população superior a 7,2 bilhões de habitantes, e que com todos os impactos já causados ao planeta, já tenhamos ultrapassado a sua capacidade de suporte. Ou seja, estamos vivendo em um momento da história deste planeta de recursos finitos, em que estamos consumindo demais, poluindo demais, destruindo as cadeias de vida que nos possibilitam continuar vivendo. Então, construir sustentavelmente, requer que levemos tudo isso em consideração e repensemos, inclusive, a forma como estamos transformando o ambiente natural em ambiente construído, dentro dos limites da capacidade de suporte do planeta, ressalta o autor.

Tem-se que, o Conselho Internacional da Construção - CIB aponta a indústria da construção como o setor de atividades humanas que mais consome recursos naturais e utiliza energia de forma intensiva, gerando consideráveis impactos ambientais. Além dos impactos relacionados ao consumo de matéria e energia, há aqueles associados à geração de resíduos sólidos, líquidos e gasosos.

Estima-se que mais de $50 \%$ dos resíduos sólidos gerados pelo conjunto das atividades humanas sejam provenientes da construção. Tais aspectos ambientais, somados à qualidade de vida que o ambiente construído proporciona, sintetizam as relações entre construção e meio ambiente. Portanto, o setor da construção civil tem papel fundamental para a realização dos objetivos globais do desenvolvimento sustentável. Frente esta realidade, busca-se minimizar os impactos ambientais provocados pela construção civil, através do paradigma da construção sustentável.

No entendimento da Agenda 21, a construção sustentável em países em desenvolvimento, define-se como "um processo holístico que aspira a restauração e manutenção da harmonia entre os ambientes natural e construído, e a criação de assentamentos que afirmem a dignidade humana e encorajem a equidade econômica". O conceito transcende a sustentabilidade ambiental, para agregar a sustentabilidade econômica e social, enfatizando o valor da qualidade de vida dos 
indivíduos e das comunidades.

\section{DESAFIOS DA CONSTRUÇÃO CIVIL}

Assim sendo, os desafios para o setor da construção são diversos, porém, em síntese, consistem na redução e otimização do consumo de materiais e energia, na redução dos resíduos gerados, na preservação do ambiente natural e na melhoria da qualidade do ambiente construído.

Para tanto, o Ministério do Meio Ambiente (2017), aponta a necessidade de:

Mudança dos conceitos da arquitetura convencional na direção de projetos flexíveis com possibilidade de readequação para futuras mudanças de uso e atendimento de novas necessidades, reduzindo as demolições;

Busca de soluções que potencializem o uso racional de energia ou de energias renováveis;

gestão ecológica da água;

Redução do uso de materiais com alto impacto ambiental;

Redução dos resíduos da construção com modulação de componentes para diminuir perdas e especificações que permitam a reutilização de materiais;

Além disso, a construção e o gerenciamento do ambiente construído devem ser encarados dentro da perspectiva de ciclo de vida.

\section{TENDÊNCIAS ATUAIS DA CONSTRUÇÃO SUSTENTÁVEL}

As tendências atuais em relação ao tema da construção sustentável caminham em duas direções segundo o Ministério do Meio Ambiente (MMA) (2017). De um lado, centros de pesquisa em tecnologias alternativas pregam o resgate de materiais e tecnologias vernáculas com o uso da terra crua, da palha, da pedra, do bambu, entre outros materiais naturais e pouco processados a serem organizados em ecovilas e comunidades alternativas. De outro lado, empresários apostam em "empreendimentos verdes", com as certificações, tanto no âmbito da edificação quanto no âmbito do urbano. No entanto, muito edifícios rotulados como verdes refletem apenas esforços para reduzir a energia incorporada e são, em muitos outros aspectos, convencionais, tanto na aparência quanto no processo construtivo.

Para a implantação urbana, o referido ministério recomenda: adaptação à 
topografia local, com redução da movimentação de terra; preservação de espécies nativas; previsão de ruas e caminhos que privilegiem o pedestre e o ciclista e contemplem a acessibilidade universal; previsão de espaços de uso comum para integração da comunidade; e, preferencialmente, de usos do solo diversificados, minimizando os deslocamentos.

Bem como, no âmbito da edificação, prevê como essenciais: a adequação do projeto ao clima do local, minimizando o consumo de energia e otimizando as condições de ventilação, iluminação e aquecimento naturais; previsão de requisitos de acessibilidade para pessoas com mobilidade reduzida ou, no mínimo, possibilidade de adaptação posterior; atenção para a orientação solar adequada, evitando-se a repetição do mesmo projeto em orientações diferentes; utilização de coberturas verdes; e a suspensão da construção do solo (a depender do clima).

Observa que, para a escolha dos materiais de construção: a utilização de materiais disponíveis no local, pouco processados, não tóxicos, potencialmente recicláveis, culturalmente aceitos, propícios para a autoconstrução e para a construção em regime de mutirões, com conteúdo reciclado. Além disso, deve-se evitar sempre o uso de materiais químicos prejudiciais à saúde humana ou ao meio ambiente, como amianto, CFC, HCFC, formaldeído, policloreto de vinila (PVC), tratamento de madeira com CCA, entre outros. Quanto aos resíduos da construção civil, deve-se atentar para a sua redução e disposição adequada, promovendo-se a reciclagem e reuso dos materiais (MMA, 2017).

Com relação à energia, recomenda o uso do coletor solar térmico para aquecimento de água, de energia eólica para bombeamento de água e de energia solar fotovoltaica, com possibilidade de se injetar o excedente na rede pública. Sobre águas e esgoto, é interessante prever: a coleta e utilização de águas pluviais, utilização de dispositivos economizadores de água, reuso de águas, tratamento adequado de esgoto no local e, quando possível, o uso de banheiro seco (MMA, 2017).

A respeito do tratamento das áreas externas, aponta a valorização dos elementos naturais no tratamento paisagístico e o uso de espécies nativas, a destinação de espaços para produção de alimentos e compostagem de resíduos orgânicos, o uso de reciclados da construção na pavimentação e de pavimentação permeável, a previsão de passeios sombreados no verão e ensolarados no inverno 
(MMA, 2017)

\section{CONSTRUÇÃO VERDE}

Kruger e Seville (2016), definem a construção verde como um conjunto de técnicas e práticas de projetos, construção e manutenção que minimizam o impacto ambiental total de uma edificação. Os efeitos de planejamento destas etapas, tem efeitos a longo prazo diretos sobre muitos aspectos do meio ambiente.

Eficiência energética, eficiência de recursos, durabilidade, uso eficiente de água, qualidade de ambiente interno, impacto reduzido na comunidade, educação e manutenção para o proprietário, desenvolvimento local sustentável, identifica-se como sendo os princípios da construção verde. Estes deverão ser considerados em projetos, nas construções bem como nas manutenções.

\section{CONCLUSÃO}

Os governos municipais possuem grande potencial de atuação na temática das construções sustentáveis. As prefeituras podem induzir e fomentar boas práticas por meio da legislação urbanística e código de edificações, incentivos tributários e convênios com as concessionárias dos serviços públicos de água, esgotos e energia. Para contribuir com tais iniciativas, deverão seguir um conjunto de prescrições adequadas à realidade brasileira abrangendo aspectos urbanísticos e as construções. Tais como prescrições direcionadas a implantação dos ambientes urbanos, as edificações propriamente ditas, quanto a escolha dos materiais das construções, a escolha da energia, bem como quanto as áreas externas desde paisagismo aos matérias de pavimentação das rodovias. É preciso pensar também na fabricação dos materiais de construção. Um dos maiores responsáveis pelas emissões de $\mathrm{CO} 2$ é a fabricação de cimento. Apresentam CRUZ, GONÇALVES, SILVA, et al (2004) em sua pesquisa, o desenvolvimento de uma ferramenta de análise da sustentabilidade energética e ambiental em edificações, com o objetivo de avaliar o consumo energético dos materiais de construção, tendo como parâmetro dois indicadores, tais como o energético - representado pelo conteúdo energético dos insumos $(\mathrm{kWh} / \mathrm{m} 2)$ e o indicador ambiental - emissões de $\mathrm{CO} 2$ (tCO2/m2). 
Destacam os autores que os materiais que participam mais ativamente na produção de $\mathrm{CO} 2$ baseou-se na seleção dos setores mais significativos: a Indústria do Cimento, Aço, Cerâmica e Agregados, analisadas segundo as fontes de energia utilizadas na produção e o seu respectivo consumo energético.

Cabe refletir que, para atender ao enquadramento de construção verde precisa-se buscar toda informação técnica científica que venha comprovar a qualidade desde a adoção de métodos construtivos quanto dos materiais a serem utilizados nas edificações. Concluindo-se que, para buscar-se uma construção que venha comungar com os dogmas da sustentabilidade ambiental, antes de mais nada requer uma internalização por parte dos profissionais ligados a construção civil, seja na etapa de planejamento, construção ou manutenção das obras. E para tanto, assumir uma postura diferenciada das tradicionais, ou seja, uma postura de forma integrada, e porque não dizer holística no fundamento das diretrizes que definirão o destino das futuras construções e dos espaços urbanos de nossos municípios. Destacando-se que esse é um tema que não se esgota aqui, mas que deverá persistir e aprofundar cada vez mais, para que as mudanças sejam consolidadas.

\section{REFERÊNCIAS}

BRASIL. Ministério do Meio Ambiente. Construção Sustentável. Brasília, 2017.

BUENO, Liane da Silva. Estudo em Áreas de Ocupação Urbana com Fatores de Risco: O Caso do Bairro Córrego Grande - Florianópolis/SC. Dissertação (Programa de Pós Graduação em Engenharia Civil), Universidade Federal de Santa Catarina, 2000.

CARDÃO, Celso. Técnica da Construção. Vol1. 8 ed. Belo Horizonte: Ed. Engenharia e Arquitetura, 1988.

CRUZ, Andrea Borges de Souza; GONÇALVES, Jardel Pereira; SILVA, Neilton Fidelis da. et al. Avaliação da Sustentabilidade Energética e Ambiental em Edificações.

Artigo apresentado na I Conferência Latino-Americana de Construção Sustentável x Encontro Nacional de Tecnologia do Ambiente Construído. Disponível em:

ftp://ip20017719.eng.ufjf.br/Public/AnaisEventosCientificos/ENTAC_2004/trabalho s/PAP0725d.pdf. Acesso em: dez. 2017.

CUNHA, Sandra Baptista da; GUERRA, Antonio José Teixeira. A Questão Ambiental: 
Diferentes Abordagens. Rio de Janeiro: Bertrand brasil, 2003.

KRUGER, Abe; SEVILLE, Carl. Construção Verde - Princípios e Práticas na Construção Residencial. São Paulo: Editora Cengage Learning, 2016.

MARICATO, Ermínia. Melancolia na desigualdade urbana. Disponível em: https://erminiamaricato.net/2017/05/16/melancolia-na-desigualdade-urbana/. Acesso: dez. 2017.

SATTLER, Miguel A. Habitações de baixo custo mais sustentáveis: A Casa Alvorada e o Centro Experimental de Tecnologias Habitacionais Sustentáveis. Porto Alegre: ANTAC, 2007 (Coleção Habitare, 8). 448 p.

SATTLER, Miguel A. Mix Sustentável - Edição 05/V3.N.1 | 2017. Disponível em: http://mixsustentavel.paginas.ufsc.br/files/2017/05/Mix-Sustenta\%CC\%81vel-5Entrevista-3.pdf. Acesso em: Dez 2017.

SPERB, M. R. Avaliação de tipologias habitacionais a partir da caracterização de impactos ambientais relacionados a materiais de construção. 2000. $149 \mathrm{f}$. Dissertação (Mestrado em Engenharia) - Escola de Engenharia, Universidade Federal do Rio Grande do Sul, Porto Alegre, 2000. 